\title{
Effect of Voltage-Gated Calcium Channels (Cav) Blocker on Ovariectomy Induced Osteoporosis in Rats
}

\author{
Vijay Rajeshwarrao Chidrawar ${ }^{*}$, Abdulkhaliq Jassem Alsalman², Sibghatullah Muhammad Ali Sangi \\ 'Department of Pharmacology and Toxicology, Northern Border University, Rafha, KINGDOM OF SAUDI ARABIA. \\ 2Department of Clinical Pharmacy, Northern Border University, Rafha, KINGDOM OF SAUDI ARABIA.
}

\begin{abstract}
Objective: The present study was conducted to investigate the effect of two different doses of two calcium channel blockers i.e. verapamil and nifedipine on genesis and control of osteoporosis by considering various biochemical and bone parameters against ovariectomized (OVX) rat model. Methods: We have used total 42 female albino Wistar rats; one group of 6 animals was kept as Sham operated group. OVX was perform on 36 rats, after 14 days of recovery period; 36 OVX rats were equally and randomly divided into 06 groups, 4 groups for verapamil and nifedipine (two doses for each); one as disease control other is treated as standard. On $41^{\text {st }}$ day, various parameters evaluated. Results: Low dose of verapamil treated group have $\mathrm{P}<0.01$ significant improvement in bone development; increasing in the bone density, breaking strength and maintaining serum calcium, phosphorous and ALP level. It also reduced the osteoclast count and maintained normal bone architecture. Conclusion: From the above study we conclude that there is involvement of specific Cav 1.1 and Cav 1.3 channels
\end{abstract}

on rat osteoblast cells. Protection offered by low dose of verapamil possibly by controlling entry of $\mathrm{Ca}^{2+}$ ions through these channels, inhibiting osteoclast formation and extending osteoblast survival.

Key words: OVX, Osteoblast, Voltage-gated calcium channels, Verapamil, Nifedipine.

Correspondence :

Dr. Vijay R. Chidrawar,

Department of Pharmacology and Toxicology, Northern Border University, Rafha, KINGDOM OF SAUDI ARABIA.

Phone number: +966-580665011

E-mail: vijay_pharmacology@yahoo.com

DOI: 10.5530/jyp.2016.4.21

\section{INTRODUCTION}

Osteoporosis is an emerging and socioeconomic threat characterized by a systemic impairment of bone mass, strength, and micro architecture, which increases the propensity of fragility fractures. ${ }^{1}$ Hypertensive patients have an increasing risk of bone fracture compared with normotensive subjects; an increased urinary calcium excretion and a reduced bone density detected in hypertensive patients. ${ }^{2,3}$ Pharmacoepidemiological case-control studies indicated that the treatment with thiazide diuretics, beta-blockers, angiotensin-converting inhibitors, calcium channel blockers is associated with a significantly reduced risk of fractures. ${ }^{4,5}$ However, basic data supporting these clinical observations are limited. A variety of different $\mathrm{Ca}^{2+}$ permeable channels that co-exist in the plasma membrane plays major roles in the entry of extracellular $\mathrm{Ca}^{2+}$. The free concentration of the $\mathrm{Ca}^{2+}$ ion in the cytosol involves the regulation of mechanisms necessary for the short-term regulation of cell functions like contraction, excitation, secretion which account for many physiological processes. ${ }^{6}$ The Osteoblasts derived from mesenchymal stem cells, plays a pivotal role in bone formation is might be mediated through voltage-gated calcium channels. ${ }^{7}$ Intracellular calcium concentration, at least part of which is decreased by calcium channel blockers (CCB'), has been shown to be increased by various bone regulatory factors, such as vitamin $\mathrm{D}_{3}^{8,9}$ parathyroid hormone ${ }^{8,10}$ and prostaglandin $\mathrm{E}_{2}{ }^{8,11}$ These factors also alter osteoblast differentiation ${ }^{12,13}$ thus; it shows that signaling through the L-type calcium channel may be important for osteoblast functions. All these above facts suggests that involvement of calcium channels in the bone remodeling, so this study is undertaken to exploit their detail role and development of new strategies for treatment of osteoporosis.

Ovariectomy induced bone loss in rats is a well-accepted model for investigating agents that could help to prevent osteoporosis because the similar pathophysiologies of bone loss caused by ovariectomy in this animal model and by postmenopausal osteoporosis in women have been extensively examined. ${ }^{14,15}$ The present study conducted to investigate the effect of two doses of nifedipine and verapamil on serum biochemical, bone parameters and histopathological observation of bone during postmenopausal osteoporosis in ovariectomized rat model. ${ }^{16}$

\section{MATERIALS AND METHODS}

Chemicals: Nifedipine and verapamil $\mathrm{HCl}$ were purchased from the Sigma Aldrich, USA. Ketamine, Estradiol valerate, Tramodol, Xylazine, Catguts, EDTA blood collecting vials were procured from the local market while Calcium Kit, Phosphate Kit, Bone specific ALP kit and Tartrateresistant acid phosphatase (TRAP) were purchased from human Diagnostics worldwide.

Instruments: DEXA using a Hologic QDR-1000 X-ray bone densitometer, Vernier calipers, Trinocular microscope, Semi-Autoanalyser (Carex), muffle furnace, Catgut (2.0) etc.

\section{Animals}

Forty two female Wistar albino rats weighing 180-200 g were acquired from the central animal house facility, Northern Border University, Saudi Arabia. Animals are housed in cages in a room maintained under controlled conditions of constant temperature and relative humidity of $21 \pm 1^{\circ} \mathrm{C}$ and $50-55 \%, 12: 12 \mathrm{Hr}$ light/dark cycle. The rats were acclimatized for 10 days, had free access to chow and water. Nations NCBE (National Committee of Bio Ethics) guidelines were strictly followed and the project is approved by the Institutional animal ethical committee (IAEC), (Ref: 5-1436-6-1).

Animal grouping and dosing: Out of 42 animals OVX surgery was performed on 36 animals by keeping one group as normal control. Fourteen days after ovariectomy 36 animals were randomly divided in 6 groups by considering two doses for verapamil and nifedipine (high and low dose) and one group as disease control and other group was served standard and treated with estradiol valerate. 
Doses of verapamil and nifedipine were selected based upon the FDA guideline on the estimation of the safe starting dose in human and animals. ${ }^{17}$

Induction of Osteoporosis: Osteoporosis wasinduced bilateral ovariectomy. All operated animals were maintained for 14 days and for initial first three days after surgery animal were treated with gentamicin $(10 \mathrm{mg} / \mathrm{kg}$, i.m. $)^{17}$ and tramadol $(25 \mathrm{mg} / \mathrm{kg}$, s.c. $) .{ }^{18}$ to avoid any post-operative infection and pain respectively.

\section{Ovariectomy surgery procedure}

Ovariectomy was made by two dorso-lateral incisions, approximately $1 \mathrm{~cm}$ long above the ovaries. With the use of a sharp dissecting scissors, the skin was cut almost together with the dorsal muscles and the peritoneal cavity was thus accessed. After peritoneal cavity was accessed, the ovary was found, surrounded by a variable amount of fat. The surgery was done under anesthesia, using a Ketamine $80 \mathrm{mg} / \mathrm{kg}$, Xylazine $5 \mathrm{mg} / \mathrm{kg}$ intraperitonially. The connection between the fallopian tube and the uterine horn was cut and the ovary moved out.

Because of muscle bleeding, its incision required suturing. ${ }^{19}$ The suturing was performed by using catgut. Recovery period of 14 days, the dosing was started from $15^{\text {th }}$ day.

All the drugs were administered once daily for 40 successive days and on $41^{\text {st }}$ day various parameters were studied like physical parameters of bone, blood chemistry, histopathological examination and osteoclast count were done. Refer Table 1.

Induction of Osteoporosis in surgically operated animals was confirmed by performing vaginal smear test.

\section{Vaginal smear test}

The two most commonly used methods of obtaining vaginal cell samples are:

a) Lavage or washing with saline or water from a pipette.

b) Swab or cotton bud (moistened with saline or water).

a. Vaginal smears were carried out to monitor cellular differentiation and to evaluate the presence of leukocytes, nucleated epithelial cells, or cornified cells. Vaginal smear samples were collected between 08.00 and $10.00 \mathrm{am}$ daily. The vaginal smears were prepared by washing with $10 \mu \mathrm{l}$ of normal saline $(\mathrm{NaCl} 0.9 \%)$ and were then thinly spread on a glass slide. They were allowed to dry at room temperature and then stained using Methylene blue dripping. The slides were rinsed in distilled water after $30 \mathrm{~min}$ and allowed to dry. The smears were studied using the light microscope $(40 \times)$ and the cell type and their relative numbers were recorded.

Vaginal smear cell counts were performed on 100 cells randomly. The percentage of cornified cells was determined according to following formula: ${ }^{20}$

There was no significant difference in the percentage of cornified cells between the groups; it confirmed a menopausal pattern in OVX rats.

\section{Determination of Serum parameters}

After 40 days successive treatment on $41^{\text {st }}$ various serum parameters like Serum calcium, phosphorus and alkaline phosphatase (ALP) were analyzed as per the method prescribed by Miller, 1994 et.al. ${ }^{21}$ (Refer Figure 1 and 2).

\section{Bone Parameters}

Percentage of Cornified Cells $=\frac{\text { Cornified Cells }}{\text { Cornified Cells }+ \text { Nucleated Cells }+ \text { Leucocytes }} \times 100$

On $41^{\text {st }}$ day rats were sacrifices by over doses of $\mathrm{CO}_{2}$ inhalation and right femur, right tibia and $4^{\text {th }}$ lumbar vertebrae were isolated from all rats.

\begin{tabular}{cccc}
\multicolumn{4}{c}{ Table 1: Animal grouping, treatment and doses selected as follows } \\
\hline Group No & Treatment & Dose & ROA \\
\hline Group I & Distilled Water & $10 \mathrm{ml} / \mathrm{kg}$ b.w. & p.o. \\
Group II & OVX+Distilled Water & $10 \mathrm{ml} / \mathrm{kg} \mathrm{b.w.}$ & p.o. \\
Group III & OVX+Estradiol valerate & $0.1 \mathrm{mg} / \mathrm{kg} \mathrm{b.w.}$ & i.m. \\
Group IV & OVX+nifedipine-H & $2.11 \mathrm{mg} / \mathrm{kg} \mathrm{b.w.}$ & p.o. \\
Group V & OVX+nifedipine-L & $1.05 \mathrm{mg} / \mathrm{kg} \mathrm{b.w.}$ & p.o. \\
Group VI & OVX+verapamil-H & $4.22 \mathrm{mg} / \mathrm{kg}$ b.w. & p.o. \\
Group VII & OVX+verapamil-L & $2.11 \mathrm{mg} / \mathrm{kg}$ b.w. & p.o. \\
\hline
\end{tabular}

p.o. $=$ per oral, $\mathrm{ROA}=$ Route of administration, b.w. $=$ Body weight, $\mathrm{H}=$ High dose, $\mathrm{L}=$ Low dose.

2.7.1 Measurement of bone Weight, length and outer diameter of diaphysis right Femur: Isolated right femur was cleaned to remove all surrounding tissues. Bones were kept in the hot oven at $52^{\circ} \mathrm{C}$ to achieve constant weight. Dry weight of the right femur was calculated by using $0.01 \mathrm{mg}$ weighing precession digital balance and recorded. The bone length, outer diameter of diaphysis of right femur and tibia were measured using Vernier calipers. ${ }^{22}$ (Refer Figure 3, 4, 5).

\section{Bone mineral density (BMD) measurement by dual energy X-ray absorptiometry (DEXA):}

In this study bone mineral density measurements was performed by using Ex vivo method at the end of the study in a double blind approach by using a Hologic QDR-1000 X-ray bone densitometer (dual X-ray source of 70 and $140 \mathrm{kVp}$ ) and an ultrahigh resolution software program with $0.0254 \mathrm{~cm}$ line spacing and a point resolution of $0.0127 \mathrm{~cm}$. This model software enables calculation of mineral content at any desired region, within the image. Right femora of each rat in all groups, were placed on the imaging positioning tray and scanned four times to avoid any errors due to placing position of the sample. The image of the mineral content within the path of this beam is generated by a scanning device. This enables calculation of the total integrated mineral content within the cross-section of the mineralized region, expressed as grams per unit area. For all bone mineral density calculations were done and compared with normal control and disease control groups (Refer Figure 6).

The breaking strength of right femur, tibia and $4^{\text {th }}$ lumbar vertebrae were performed by breaking strength apparatus (Monsanto). The fresh bones and vertebrae were placed in hardness compressor, until it fractured. The reading were recorded in Newton's ${ }^{23}$ (Refer Figure 7).

Histopathology of femur bone and osteoclast examination: The left femur were fixed in $10 \%$ neutral formalin for $12 \mathrm{hr}$ at $4^{\circ} \mathrm{C}$, decalcified in $5 \%$ ethylenediaminetetracetict acid (EDTA) for 7 days, embedded in paraffin and cut into longitudinal section of $5 \mu \mathrm{m}$ thickness. The section were stained with haematoxylin and eosin and tartrate-resistant acid phosphatase (TRAP), a cytochemical marker for osteoclast and finally counter stained with haematoxylin. The number of positively stained osteoclast in the section of the median portion of the whole femora was enumerated for the all groups. ${ }^{22,23}$ (Figure 8 and 9).

\section{Statistical Analysis}

The results are expressed as mean \pm SEM. Comparisons between the treatment groups and positive control; positive control and control were performed by one way analysis of variance (ANOVA) followed by Dunnett test. In all tests the criterion for statistical significance was $\mathrm{p}<0.05$ (95\% level) and $\mathrm{p}<0.01$. The analysis was performed by using Graph pad Prism V. 


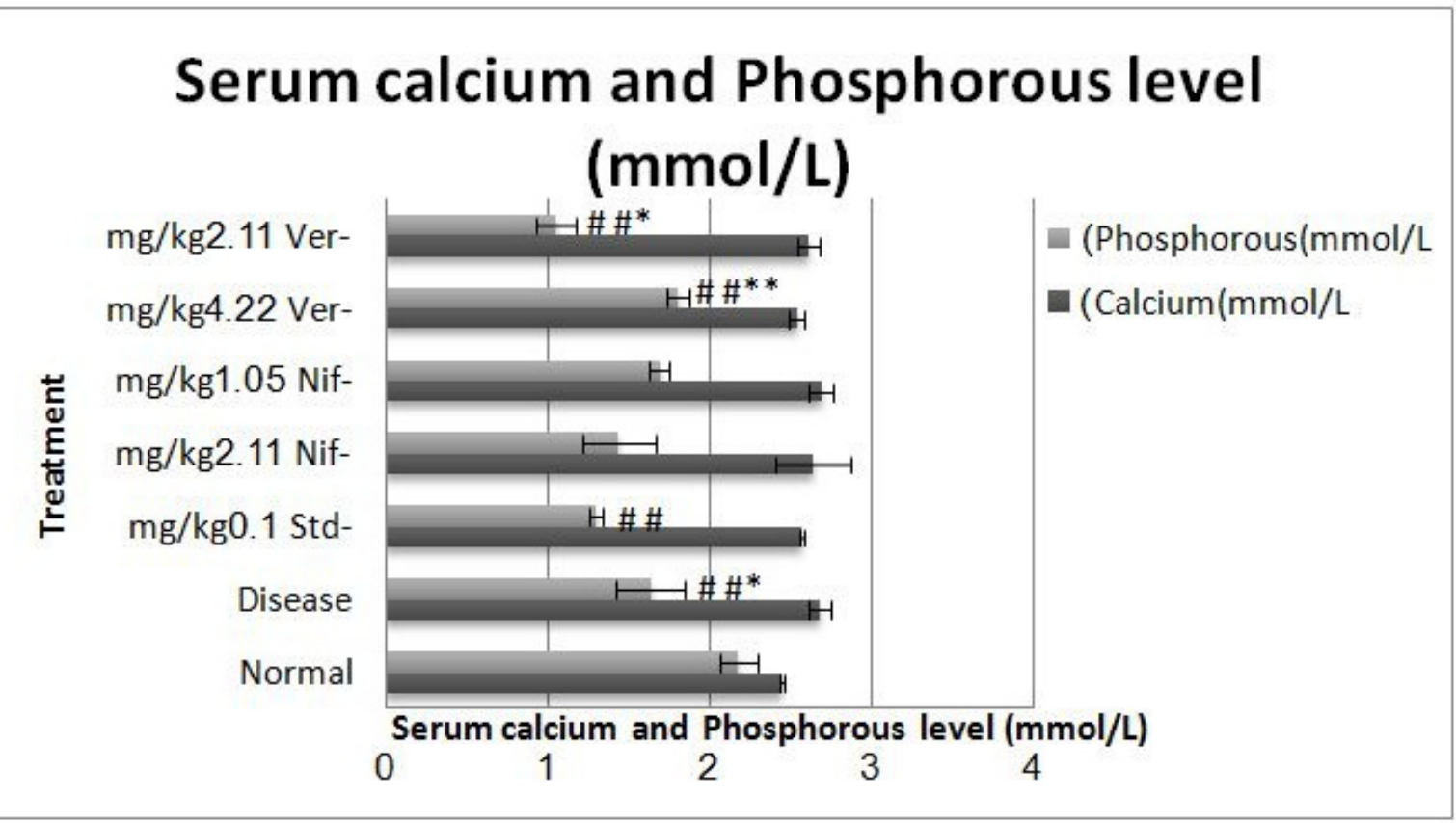

Figure 1: Effect of verapamil and nifedipine on Serum Calcium and Phosphorous. level (mmol/L) on OVX Wistar rats.

All of the data obtained from the experimental groups have been compared to Ovariectomized control (Disease) and Normal (Sham-operated) rat groups. The data was analysed statistically by one-way ANOVA followed by Dunnett test using Graph pad prism version 5.0 software.

"Comparison of standard and test groups with normal control.

${ }^{*}$ Comparison of test, standard with disease control.

Values are significant at ${ }^{* *} P<0.05,{ }^{* * * *} P<0.01$ and ${ }^{* * * * *} P<0.001$.

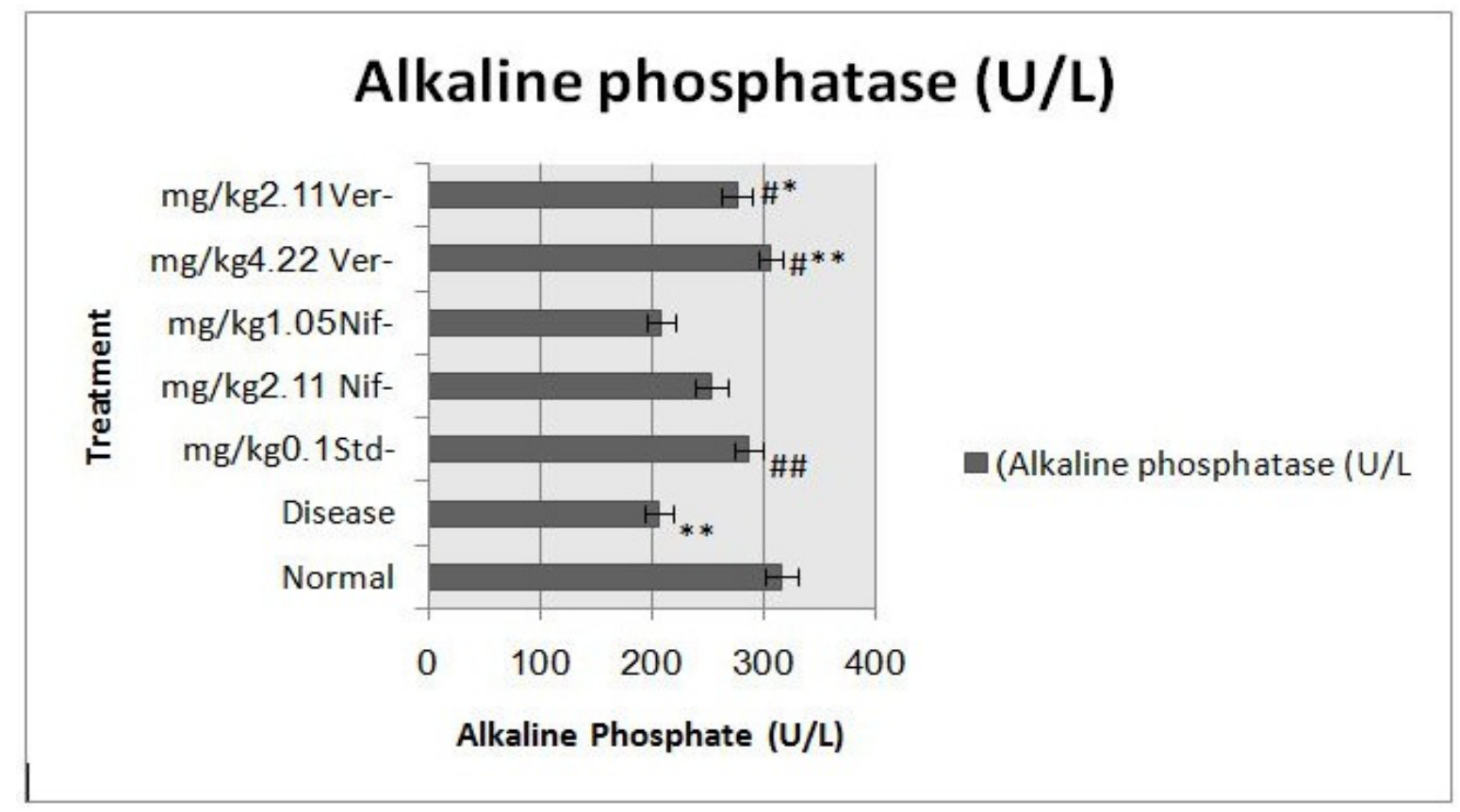

Figure 2: Effect of verapamil and nifedipine on Alkaline Phosphate (U/L) on OVX Wistar rats.

All of the data obtained from the experimental groups have been compared to Ovariectomized control (Disease) and Normal (Sham-operated) rat groups. The data was analysed statistically by one-way ANOVA followed by Dunnett test using Graph pad prism version 5.0 software.

"Comparison of standard and test groups with normal control.

*Comparison of test, standard with disease control. 


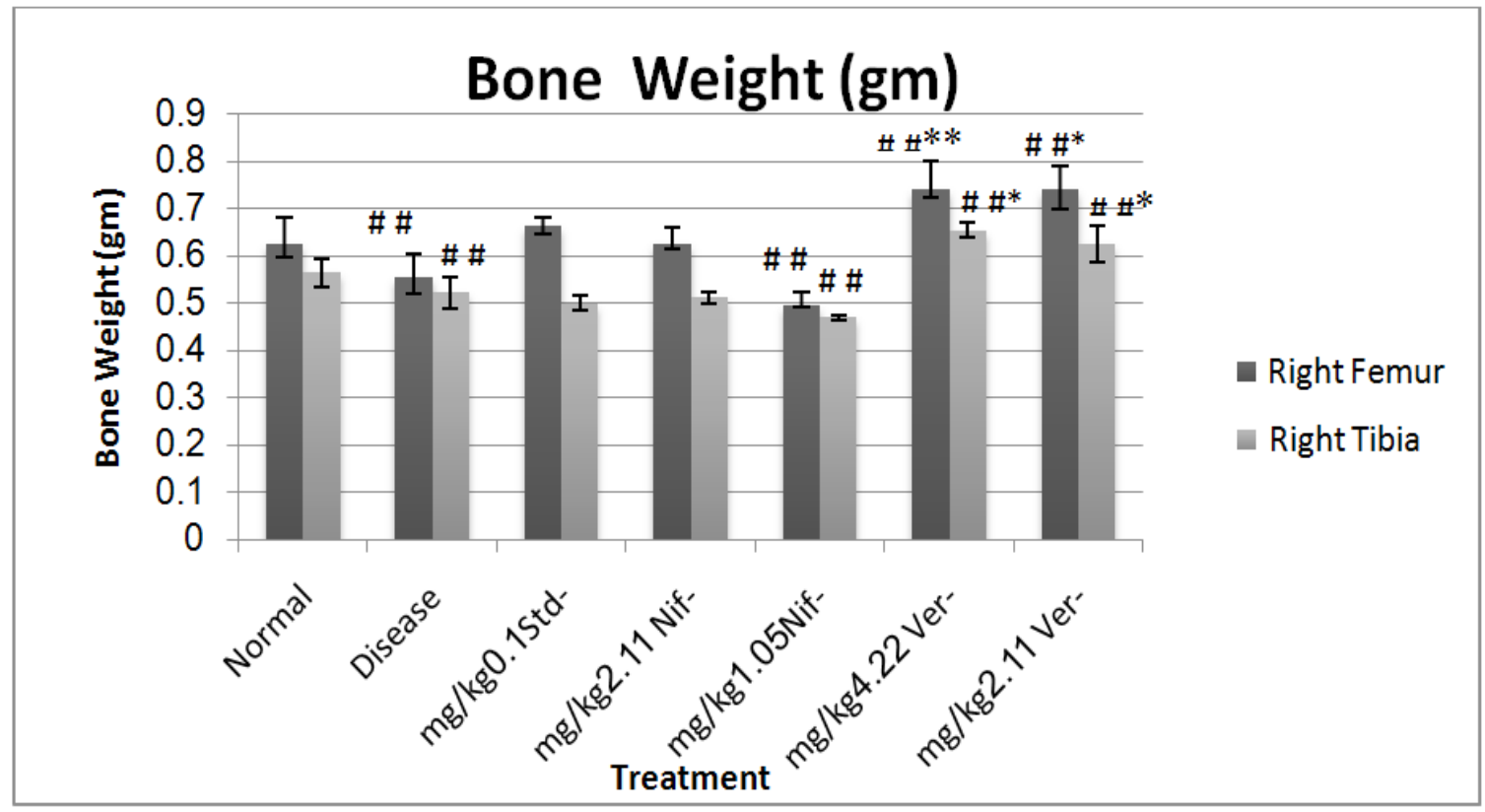

Figure 3: Effect of verapamil and nifedipine on Bone Weight (gm) on OVX Wistar rats.

All of the data obtained from the experimental groups have been compared to Ovariectomized control (Disease) and Normal (Sham-operated) rat groups. The data was analysed statistically by one-way ANOVA followed by Dunnett test using Graph pad prism version 5.0 software.

"Comparison of standard and test groups with normal control.

${ }^{*}$ Comparison of test, standard with disease control.

Values are significant at ${ }^{* *} \mathrm{P}<0.05,{ }^{* * * *} \mathrm{P}<0.01$ and ${ }^{* * * * *} \mathrm{P}<0.001$.

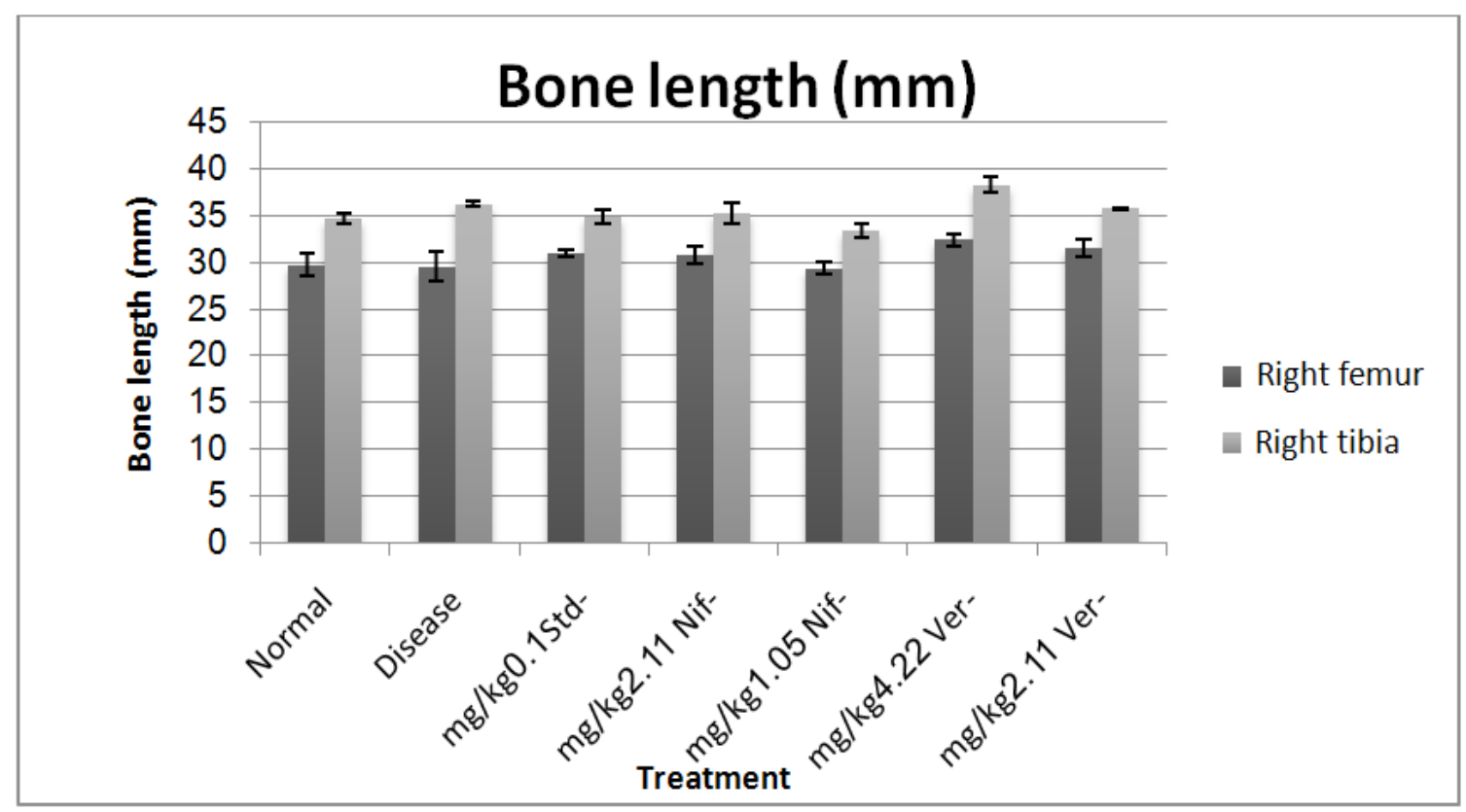

Figure 4: Effect of verapamil and nifedipine on Bone length $(\mathrm{mm})$ on OVX Wistar rats.

All of the data obtained from the experimental groups have been compared to Ovariectomized control (Disease) and Normal (Sham-operated) rat groups. The data was analysed statistically by one-way ANOVA followed by Dunnett test using Graph pad prism version 5.0 software.

"Comparison of standard and test groups with normal control.

${ }^{*}$ Comparison of test, standard with disease control.

Values are significant at ${ }^{* *} \mathrm{P}<0.05,{ }^{* * * *} \mathrm{P}<0.01$ and ${ }^{* * * * *} \mathrm{P}<0.001$. 


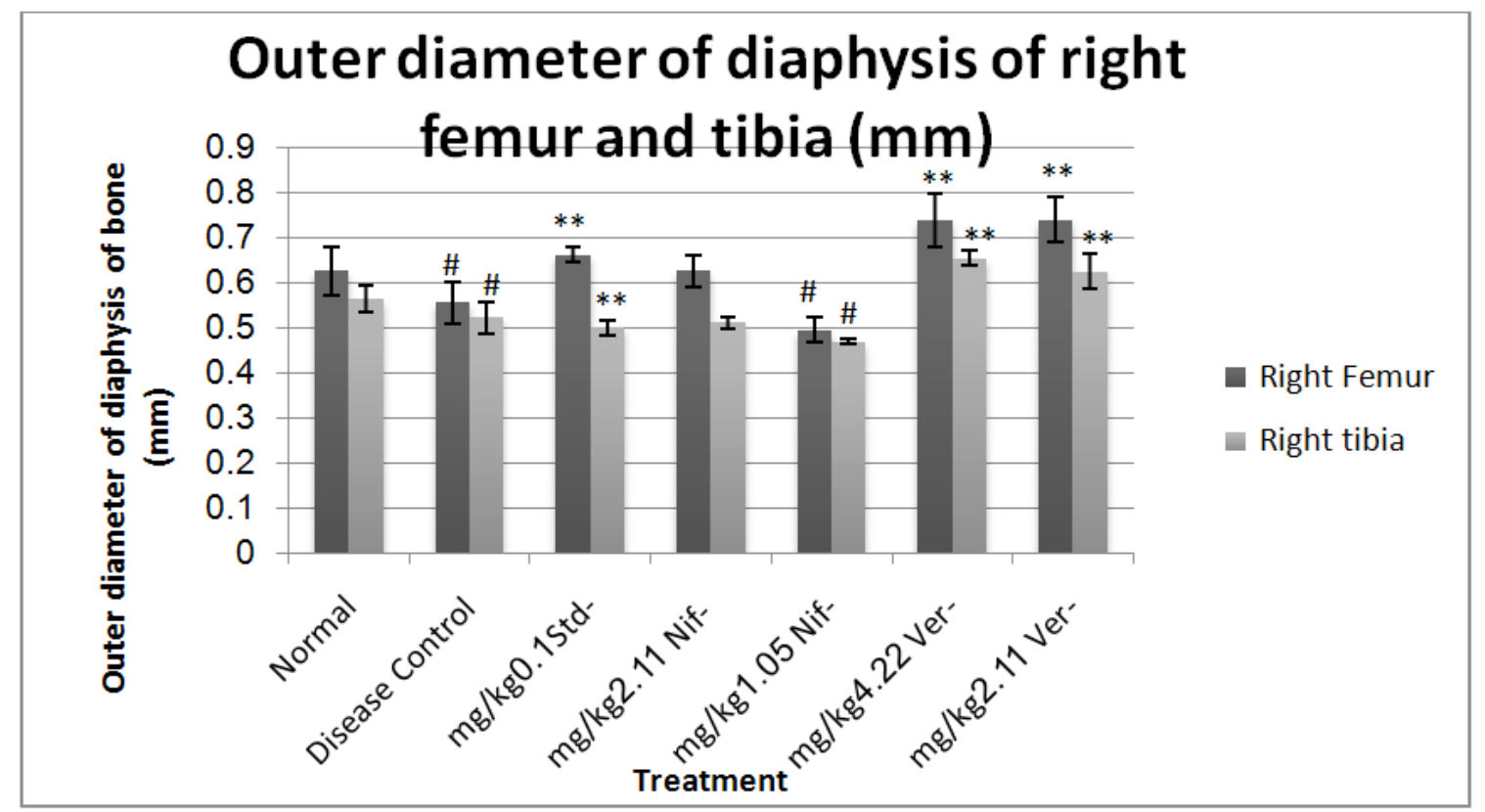

Figure 5: Effect of verapamil and nifedipine on Outer diameter of diaphysis of right femur and right tibia on OVX Wistar rats.

All of the data obtained from the experimental groups have been compared to Ovariectomized control (Disease) and Normal (Sham-operated) rat groups.

The data was analysed statistically by one-way ANOVA followed by Dunnett test using Graph pad prism version 5.0 software.

"Comparison of standard and test groups with normal control.

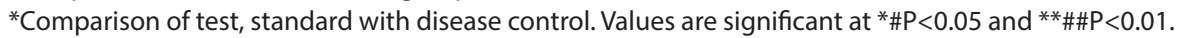

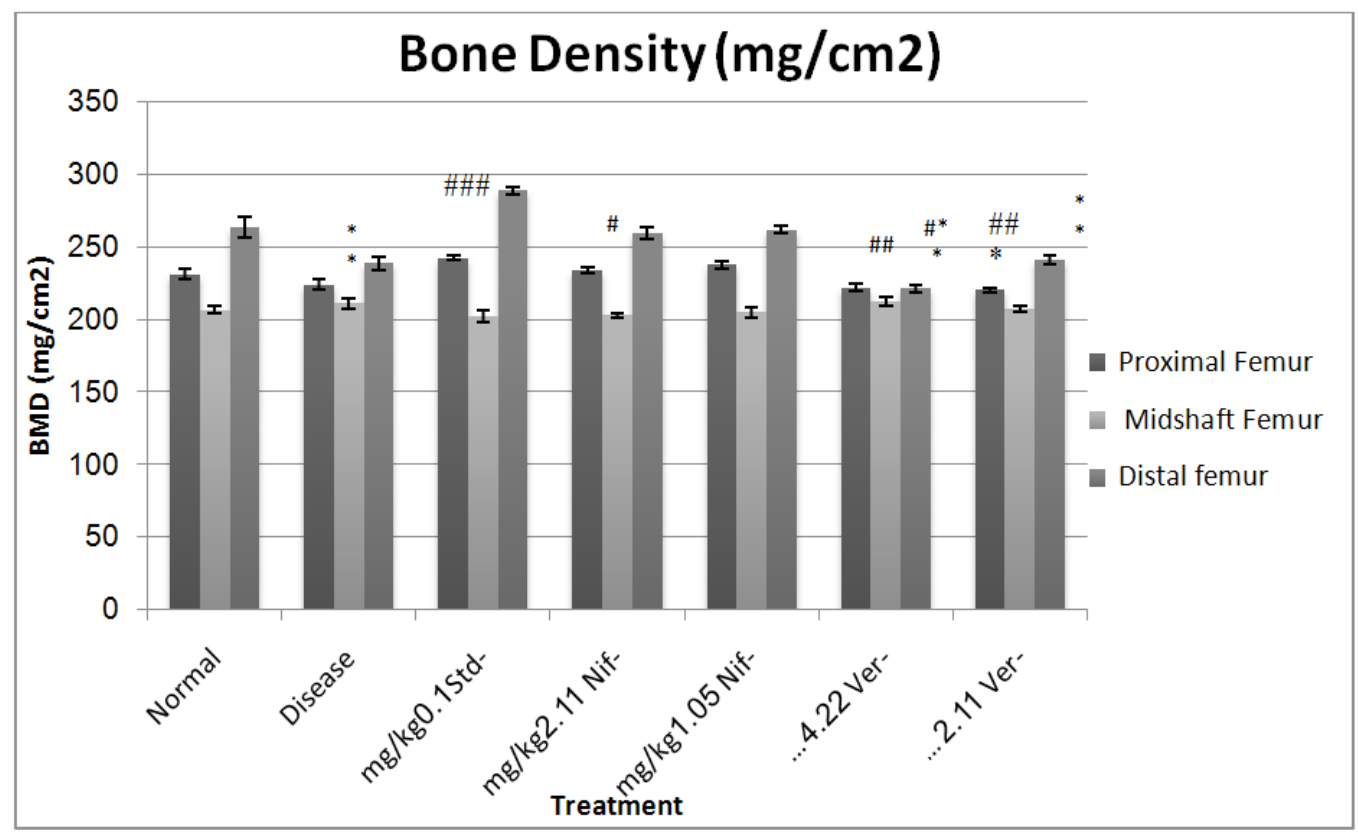

Figure 6: Effect of verapamil and nifedipine on Bone density $\left(\mathrm{mg} / \mathrm{cm}^{2}\right)$ on OVX Wistar rats.

All of the data obtained from the experimental groups have been compared to Ovariectomized control (Disease) and Normal (Sham-operated) rat groups. The data was analysed statistically by one-way ANOVA followed by Dunnett test using Graph pad prism version 5.0 software.

"Comparison of standard and test groups with normal control.

*Comparison of test, standard with disease control.

Values are significant at ${ }^{* *} \mathrm{P}<0.05,{ }^{* * * *} \mathrm{P}<0.01$ and ${ }^{* * * * *} \mathrm{P}<0.001$. 


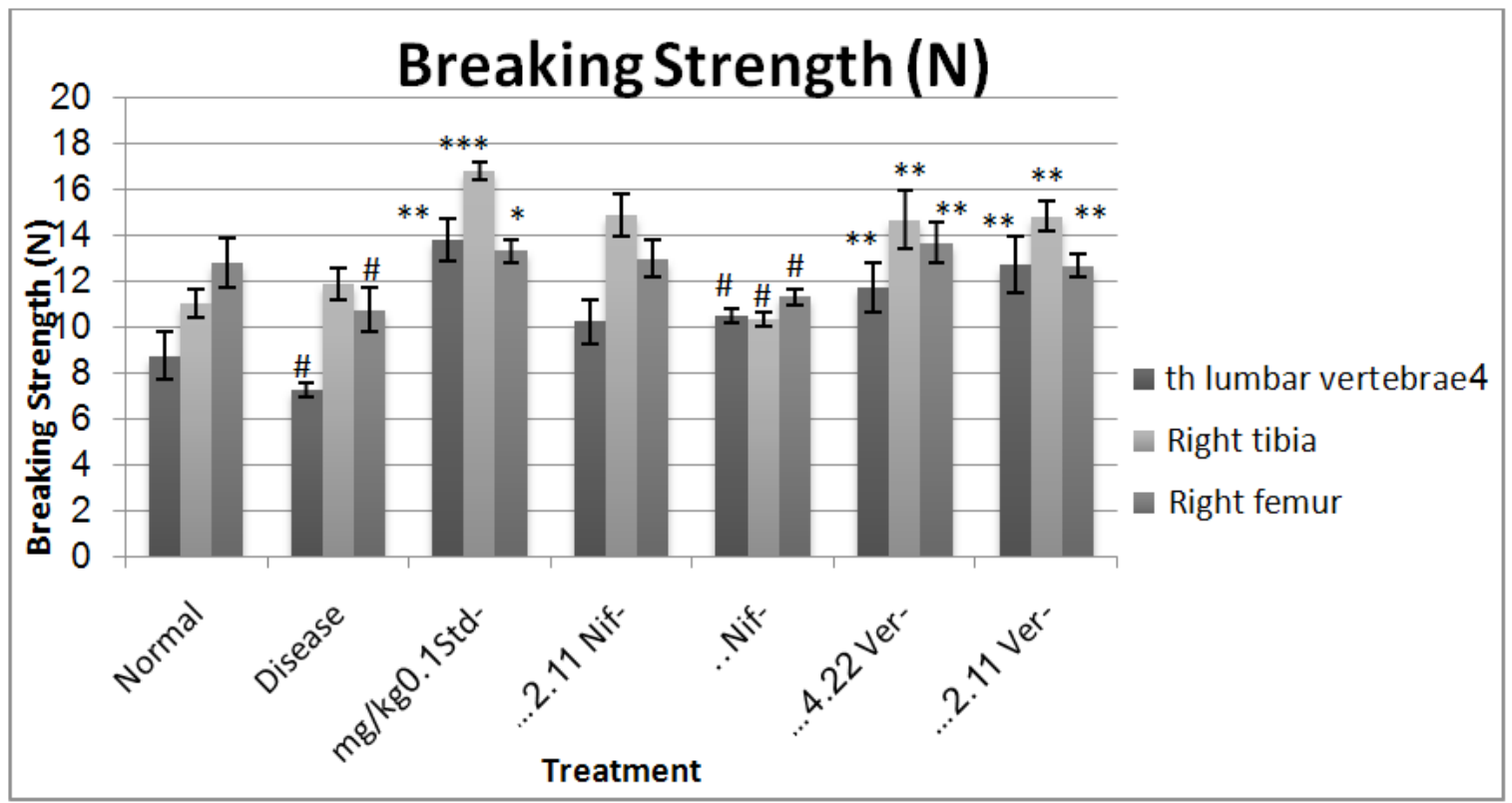

Figure 7: Effect of verapamil and nifedipine on breaking strength $(\mathrm{N})$ of $4^{\text {th }}$ lumbar, right tibia and right femer on OVX Wistar rats.

All of the data obtained from the experimental groups have been compared to Ovariectomized control (Disease) and Normal (Sham-operated) rat groups. The data was analysed statistically by one-way ANOVA followed by Dunnett test using Graph pad prism version 5.0 software.

"Comparison of standard and test groups with normal control.

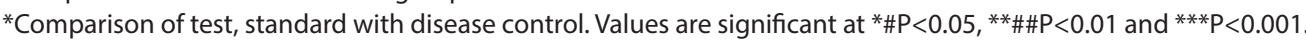

\section{RESULTS}

Effect of verapamil and nifedipine on Serum Calcium and Phosphorous level ( $\mathrm{mmol} / \mathrm{L}$ ) on OVX Wistar rats

The Serum phosphorous level was significantly $(\mathrm{P}<0.001)$ declined in Standard estradiol, nifedipine-high dose and verapamil-low dose treated when compared to normal control. The serum level of calcium significantly $(\mathrm{P}<0.01 \& \mathrm{P}<0.05)$ reduced in the verapamil high dose and low dose treated groups compared to disease control group respectively. (Figure 1).

Effect of verapamil and nifedipine on Alkaline Phosphate (U/L) on OVX Wistar rats.

The serum level of alkaline phosphatase significantly $(\mathrm{P}<0.01)$ increased in verapamil treated group compared to disease control groups in dose dependent manner (Figure 2).

Effect ofverapamil and nifedipine on Bone Weight (gm) on OVX Wistar rats.

Weight of right femur and tibia were significantly $(\mathrm{P}<0.01)$ declined by disease control and nifedipine low dose compared with normal control group. verapamil treated and standard estradiol valorate treated groups have shown significant raise in weight of right femur and tibia compared to disease control and normal control groups (Figure 3).

Effect of verapamil and nifedipine on Bone length $(\mathrm{mm})$ on OVX Wistar rats

No significant changes were observed in the bone length in any of the treatment groups (Figure 4).

Effect of verapamil and nifedipine on Bone density $(\mathrm{m} / \mathrm{v})$ on OVX Wistar rats.

Bone density was significantly $(\mathrm{P}<0.01)$ reduced by disease control and nifedipine low dose treated groups compared with normal control groups. Standard estrdiol valorate, verapamil low and high dose treated groups have shown significantly $(\mathrm{P}<0.01)$ increase in bone density compared to disease control and normal control groups (Figure 5).

Effect of verapamil and nifedipine on Outer diameter of diaphysis of right femur and right tibia on OVX Wistar rats.

Outer diameter of diaphysis of right femur and tibia was significantly $(\mathrm{P}<0.05)$ reduced by disease control and nifedipine low dose treated groups compared with normal control groups. Standard estrdiol valorate, verapamil low and high dose treated groups have shown significantly $(\mathrm{P}<0.01)$ increase in outer diameter of diaphysis of right femur and tibia compared to disease control and normal control groups (Figure 6).

Effect of verapamil and nifedipine on breaking strength $(N)$ of $4^{\text {th }}$ lumbar, right tibia and right femer on OVX Wistar rats.

Breaking strength of $4^{\text {th }}$ lumbar and right femur significantly $(\mathrm{P}<0.05)$ reduced by disease control and nifedipine low dose treated group compared with normal control group. Breaking strength of $4^{\text {th }}$ lumbar, right tibia and right femer was significantly $(\mathrm{P}<0.01)$ increased by standard eastradiolvalorate and verapamil low and high dose (Figure 7 ).

Effect of verapamil and nifedipine on histopathology of left femer on OVX Wistar rats:

Disease control group showing disturbed microarchitectural of bone. In verapamil treated group have shown protection against estrogen loss and maintained microarchitecture of the bone like standard Estradiol valerate treated group (Figure 8).

Effect of verapamil and nifedipine on osteoclast cell count of left femur bone on OVX Wistar rats:

Disease control group showing high osteoclast count indicating bone porosity and resorption. Osteoclast count is reduced by verapamil high and low dose treated group indicating protective effect against estrogen loss OVX Wistar rats (Figure 9). 


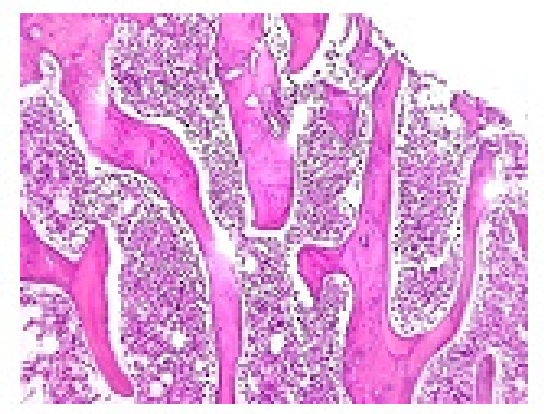

Group 1-8a: Normal control group

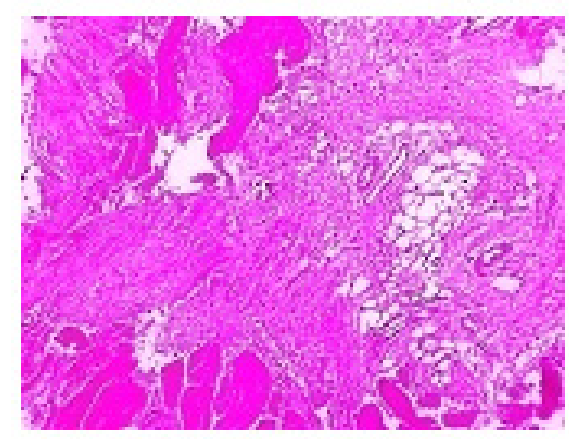

Group 3-8c: Std. Estradiol valerate $(0.1 \mathrm{mg} / \mathrm{kg}, i \mathrm{~m})$

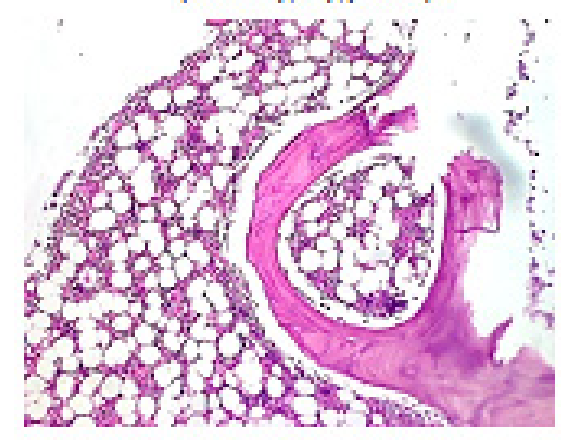

Group 5-8e:Nifedipine (1.05 mg/kg, p.o.)

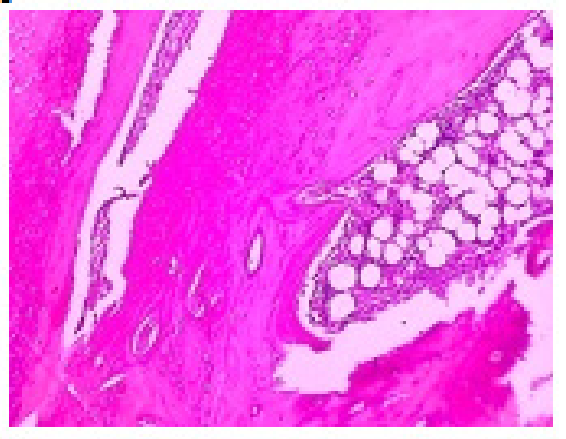

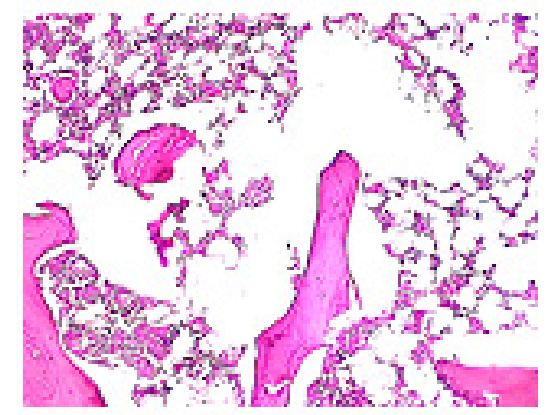

Group 2-8b: Disease control group

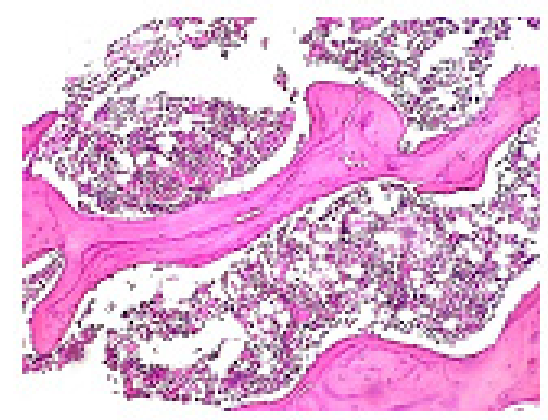

Group 4-8d:Nife dipine ( $2.11 \mathrm{mg} / \mathrm{kg}$, p.o.)

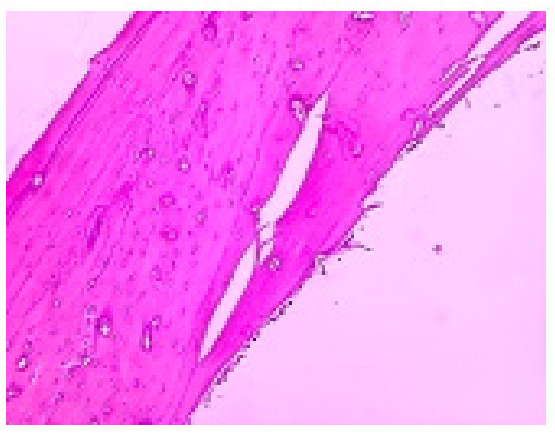

Group 6-8f: Verapamil (4.22 mg/kg, p.o.)

Group 7-8g: Verapamil $(2.11 \mathrm{mg} / \mathrm{kg}$, p.o.)

Figure 8: Effect of verapamil and nifedipine on histopathology of left femer on OVX Wistar rats.

The left femur were fixed in $10 \%$ neutral formalin for $12 \mathrm{hr}$ at $4^{\circ} \mathrm{C}$, decalcified in $5 \%$ ethylenediaminetetracetict acid (EDTA) for 7 days, embedded in paraffin and cut into longitudinal section of $5 \mu \mathrm{m}$ thickness. 


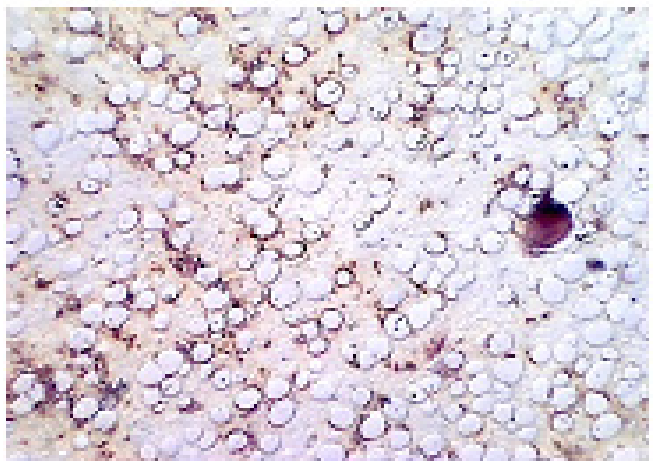

Group 1-9a: Nomal control group

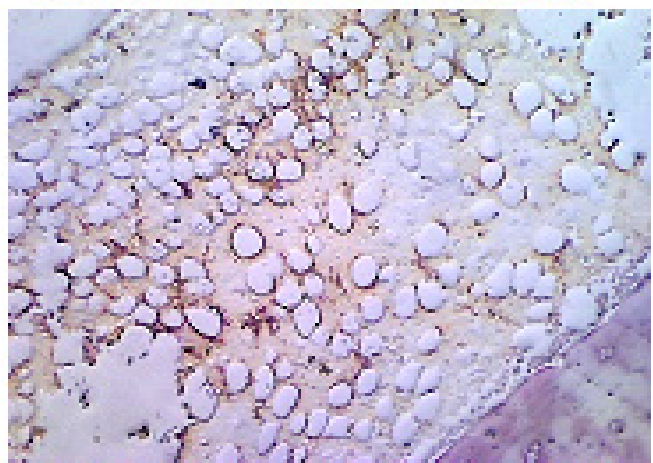

Group 3-9c: Std. Estradiol valerate (0.1 $\mathrm{mg} / \mathrm{kg}, i \mathrm{~m})$

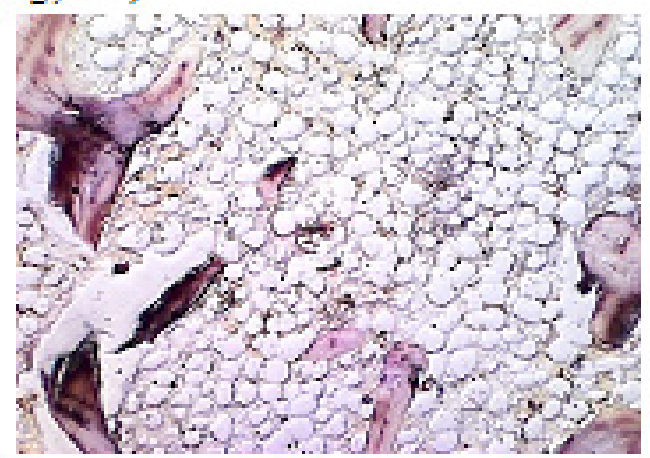

Group 5-9e:Nifedipine (1.05 mg/kg, po.)

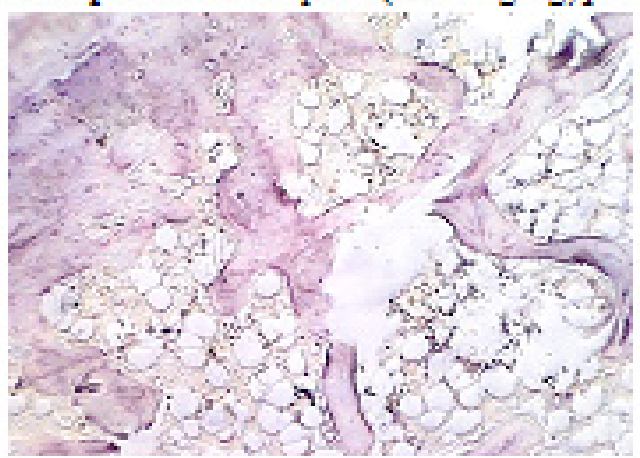

Group 6-9g: Verapamil (2.11 $\mathrm{mg} / \mathrm{kg}, p . a)$

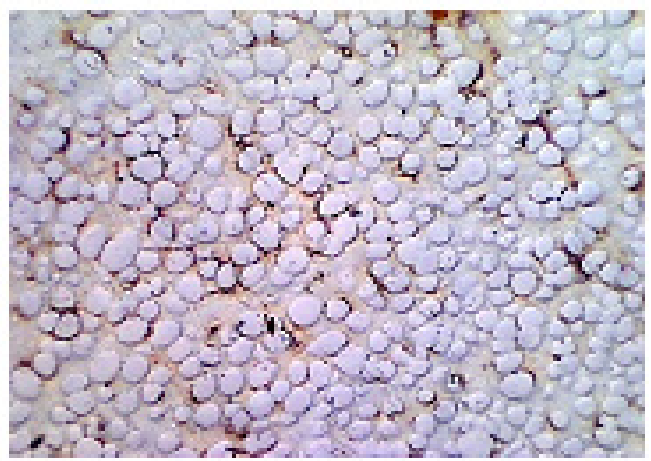

Group 2-9b: Disease control group

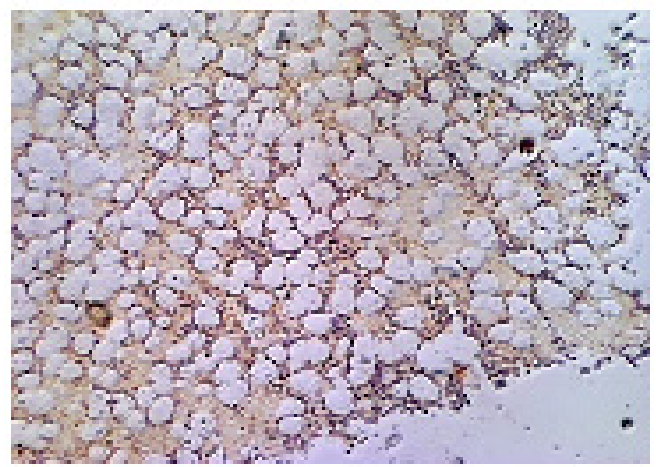

Group 4-9d:Nifedipine (2.11 mg/kg, po.)

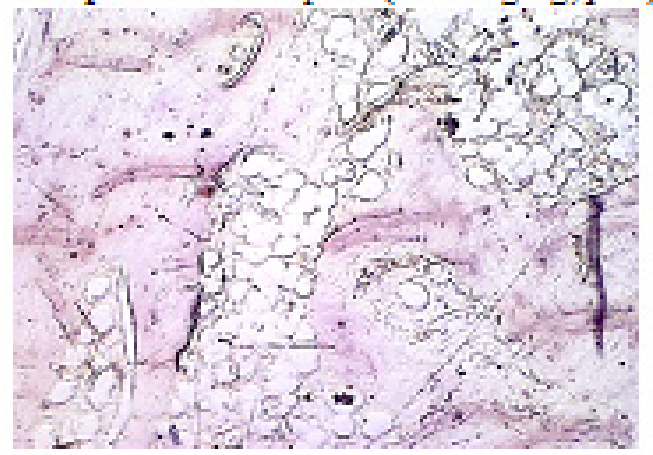

Group 6-9f: Verapamil (4.22 mg/kg, po.)

Figure 9: Effect of verapamil and nifedipine on osteoclast cell count of left femur bone on OVX Wistar rats (TRAP analysis):

The left femur were fixed in $10 \%$ neutral formalin for $12 \mathrm{hr}$ at $4^{\circ} \mathrm{C}$, decalcified in $5 \%$ ethylenediaminetetracetict acid (EDTA) for 7 days, embedded in paraffin and cut into longitudinal section of $5 \mu \mathrm{m}$ thickness. The section were stained with haematoxylin and eosin and tartrate-resistant acid phosphatase (TRAP), a cytochemical marker for osteoclast and finally counter stained with haematoxylin. The number of positively stained osteoclast in the section of the median portion of the whole femora was enumerated for the all groups and pictures were taken by using Trinocular microscope and Olympus camera ( $400 \mathrm{X}$ ). 


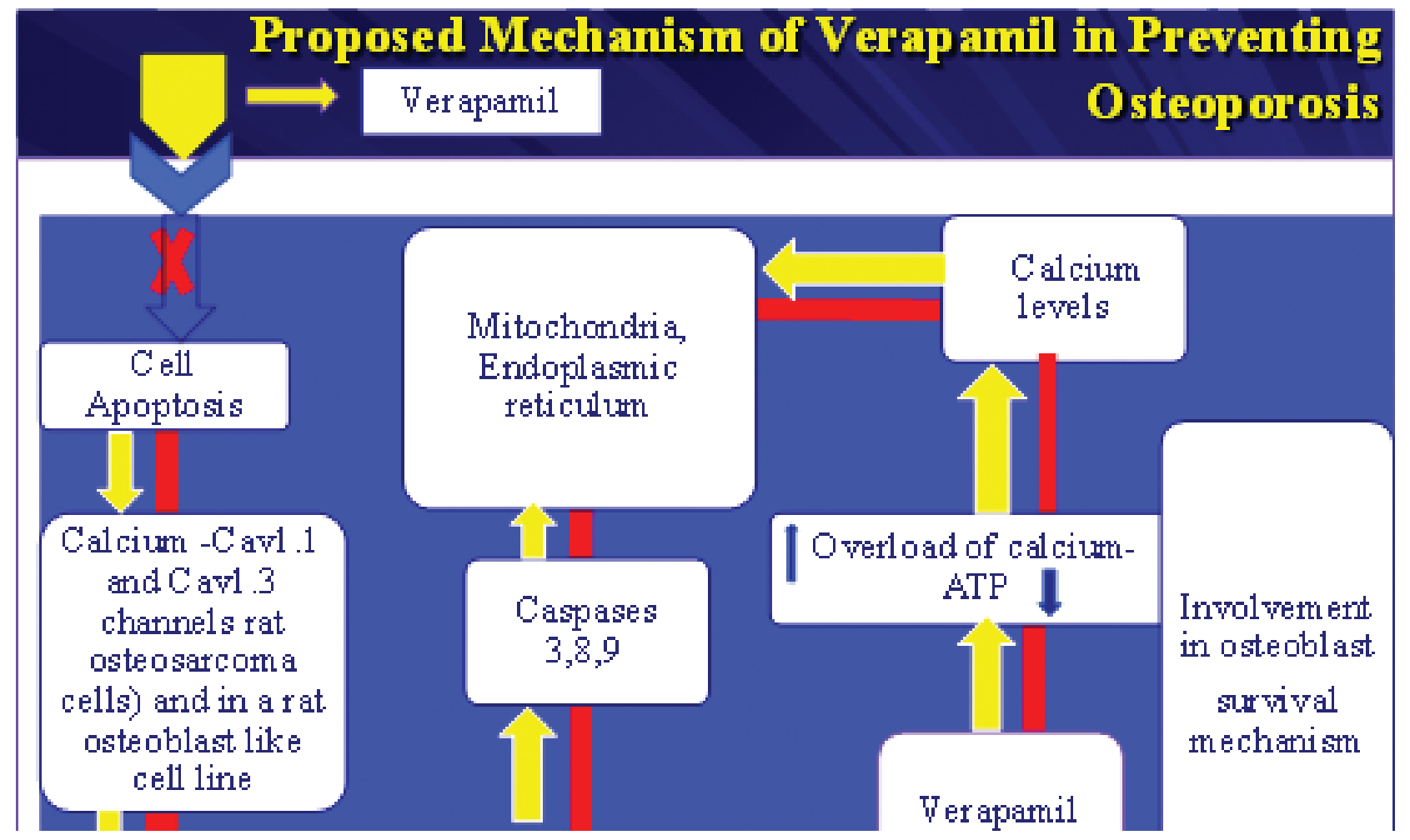

Figure 10: Proposed mechanism of verapamil as anti-osteoporosis in the management of post-menopausal osteoporosis.

\section{DISCUSSION}

Calcium is a ubiquitous second messenger involved in multiple signaling pathways mediating diverse physiological functions. The free concentration of the $\mathrm{Ca}^{2+}$ ion in the cytosol involves the regulation of mechanisms necessary for the short-term regulation of cell functions like contraction, excitation, secretion which account for many physiological processes. ${ }^{24}$ In bone, $\mathrm{Ca}^{2+}$ has a structural role, since osteoblasts deposit an extracellular matrix (ECM) that contains nucleation sites for mineral deposition but their exact role in the control of bone development and resorption is yet to be established, so in the present study we have investigated the role of two L-type $\mathrm{Ca}^{2+}$ channel antagonists i.e. nifedipine and verapamil in osteoporosis by using OVX rat model.

The test drugs verapamil and nifedipine, two doses of each and standard estradiol valerate were administered successively for 40 days. Tests drugs were administered by p.o. route while standard estradiol valerate was administered by i.m. route. To avoid circadian changes in the hormonal levels we have administered all drugs in between 9.00 AM to 10.00 AM daily.

To understand the role of these drugs in the bone regulation we have performed parameters like serum calcium, phosphorous and alkaline phosphatase levels; bone parameters like bone density and breaking strength of right femur, right tibia, $4^{\text {th }}$ lumbar vertebrae; histopathological examination and osteoclast count of left femur bone on each animal was performed.

Groups treated with verapamil have shown significant decreased level of serum calcium, phosphorous when compared with disease control group (Refer Figure 1). In all treated groups phosphorous levels are sharply decreased when compared to calcium level. The above changes are possibly because of the parathyroid hormone (PTH). Previous study reveals presence of calcium channels on parathyroid cell membrane that respond to plasma calcium, by blocking calcium channels on parathyroid membrane causes more release of PTH. Parathyroid hormone increases blood calcium level by operates negative feedback system to maintain decreased calcium level my multiple mechanisms i.e. it acts on the respective effectors results in increased number of osteoclasts by increasing bone resorption, kidneys retain calcium in blood, excrete phosphate in urine and also promotes GI absorption of calcium..$^{25,26}$

In our study we have measured serum alkaline phosphatase (ALP) level because elevated ALP indicates that there could be active bone formation occurring as ALP is a byproduct of osteoblast activity. ${ }^{27}$ Osteoblasts are specific fibroblasts that secrete and mineralize the bone matrix that's gives strength to the bone. While osteoblast differentiation several extracellular matrix proteins (procollagen I, TGF- $\beta$, and fibronectin) are produced and for matrix maturation alkaline phosphatase is more expressed by the osteoblast cells, hence increase in the serum ALP level is the clear sign of the bone formation and bone mineralization. ${ }^{28}$ In our study serum ALP level was significantly $(\mathrm{P}<0.01)$ increased by verapamil low and high doses while nifedipine treated groups there is also increase in ALP level but not significantly compared to disease control group (Refer Figure 2).

Both the test drugs are acting on L-type calcium channels, the difference in their action is may be because of their binding affinity to the specific L-type calcium channels. There are four isoforms of L-VGCCs known and affinity to the same blocker varies. Cav1.3 and Cav1.4, two isoforms of L-VGCCs, has lower affinity for nifedipine, than Cav1.2 29 Cav1.1 and Cav1.3 $3^{30}$ which are expressed on rat osteosarcoma cells ${ }^{31}$ and in a rat osteoblast like cell line ${ }^{32}$ because of these possible reasons verapamil have shown protective effect compare to nifedipine treated groups.

Verapamil treated groups shown no significant protection against bone length but bone weight $(\mathrm{P}<0.05)$ and bone density (proximal femur and 
distal femur) was significantly $(\mathrm{P}<0.01)$ increased by low and high dose of verapamil compared to disease control group (Refer Figure 3 and 4).

Post-menopausal osteoporotic women mainly affected by fractures occurred in femur bone, tibia, and $4^{\text {th }}$ lumbar vertebrae that might be because of these bones are mainly involved in support and bear more strain so we have considered breaking strength of these bones as one of the parameter. In our study verapamil low dose has shown significant $(\mathrm{P}<0.01)$ improvement in the breaking strength of right femur bone, right tibia, $4^{\text {th }}$ lumbar vertebrae compared with both disease control and sham-operated groups (Refer Figure 7) but not more than Estradiol treated group. Decreasing in the breaking strength in the disease control group indicating bone weakness, it is may be because of the more osteoclast (i.e. bone resorption) and less osteoblast (i.e. bone formation) in bone cells. These results were further confirmed by histopathological study and osteoclast count of femur bone, which supports our findings (Refer Figure 8 and 9).

Limitation of our study is that we didn't performed parameters involved in the apoptosis but based upon our finding and pharmacology of test drugs we have postulated overall mechanism. Sustained increase in intracellular calcium has been associated with apoptosis in a variety of cell systems. ${ }^{33}$ Cytosolic calcium load is kept under control by $\mathrm{Ca}^{+2}$ pump, functioning of the $\mathrm{Ca}^{++}$pump is ATP dependent which supplied by mitochondria. Loading of the mitochondrial stores by calcium beyond a certain point, however, disrupts mitochondrial function results in diminish ATP synthesis, thus reducing the energy available for the membrane pumps. This may responsible for increase in free cytosolic $\mathrm{Ca}^{+2}$ level and possibly activates the caspases proteins to initiates apoptosis. Verapamil has offered protection possibly by controlling the entry of $\mathrm{Ca}^{2+}$ ions in the osteoblast and osteosarcoma cells via Cav1.1 and Cav1.3 channels.
Based on these observations, we proposed that low dose of verapamil directly inhibited the osteoclast count and also maintained normal bone architecture via its involvement in osteoblast survival mechanism (Figure 10).

\section{CONCLUSION}

On the basis of this study we concluded that low dose of verapamil has potent anti-osteoporotic activity.

The advantage of these finding is that in age old persons many disease like hypertension, arterial fibrillation and osteoporosis co-exist together and to tackle those patient may consume many drugs together, this multiple drugs combination not only gives stress on already weaken body but also interaction in-between them may gives horrifying effects and some time it is fatal too. CCBs have been already approved by FDA and the drugs are in the market from many decades to treat many conditions. Our latest finding suggests that mono therapy with verapamil might be enough to control mild hypertension co-existed with post-menopausal osteoporosis and this mono therapy will also prevent the dreadful drug interactions.

\section{ACKNOWLEDGEMENTS}

This project was funded by Deanship of Scientific Research (DRS), Northern Border University under grant no. (1/6/1436/5). The authors would like to acknowledge the DSR technical for financial support.

\section{CONFLICT OF INTEREST}

Authors don't have any conflict of interest.

\section{ABBREVIATIONS USED}

CALP: Alkaline phosphatase; ANOVA: Analysis of variance; BMD: Bone mineral density; Cav: Voltage gated Calcium Channels; CCB': Calcium channel blockers; CRAC: $\mathrm{Ca}^{2+}$ release-activated $\mathrm{Ca}^{2+}$ channels; DEXA: Dual energy x-ray absorptiometry; ECF: Extracellular fluid; ECM: Extra Cellular matrix; EDTA: Ethylene diamine tetra cetictacid; FDA: Food drug approval; gm: gram; IAEC: Institutional animal ethical committee; L-VGCC: L-type of voltage gated calcium channels; mg: milligram; mm: millimeter; N: Nutone; NCBE: (National Committee of BioEthics); Nif: nifedipine; OVX: Ovariectomized; PTH: Parathyroid hormone; RANK: Receptor activator of nuclear factor k?; RANK-Ligand: Receptor activator of nuclear factor k?-Ligand; SOCs: Store operated channels; TGF-B: Tran forming growth factor-B; TRAP: Tartarate acid resistant phosphatase; U/L: units per liter; Ver: Verapamil; VOCs: Voltage-operated channels.

\section{ABOUT AUTHORS}

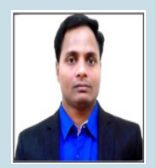

Dr. Vijay: Has vast experience in pre-clinical research and has more 11 years of involvement in academic research. He has published more than 53 research publications in various International high impact factor journals. His area of research is ion-channels and their involvement in various disease conditions like cataract, IBD, obesity, osteoporosis etc.

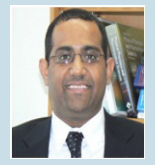

Dr. Abdul khaliq Jassem Alsalman: Is a vice dean and an assistant professor at College of Pharmacy at Northern Border University. He graduated with his Master and PhD degrees in Pharmacotherapy and Outcome Sciences at Virginia Commonwealth University (VCU)- School of Pharmacy and completed a patient safety fellowship at the Medical College of Virginia Health System at Richmond, Virginia in the United State of America. He also finished postdoctoral fellow at Virginia Commonwealth University- and an executive patient safety Fellowship at the School of Medicine Prior to going to VCU. His research and practice interests include pain management pharmacotherapy, medicationtaking behaviors, addiction studies, sickle cell anemia, mixed method research, patient-reported outcomes (PROs), scale development and psychometric evaluation, large data analysis, and pharmacoepidemiological studies.

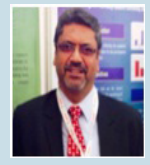

Dr. Sibghatullah: Is a health care professionalist and his qualification is MBBS, M.Phill, and PhDleading as head of the Clinical Pharmacy department at Northern Border University. He has more than 20 years of experience in teaching and published several research papers in clinical and pre-clinical domen. 


\section{REFERENCES}

1. NIH Consensus Development Panel on Osteoporosis Prevention Diagnosis, and Therapy. Osteoporosis prevention, diagnosis, and therapy. JAMA. 2001;285(6):785-95

2. Cappuccio FP, Meilahn E, Zmuda JM, Cauley JA. High blood pressure and bonemineral loss in elderly white women: a prospective study. Study of Osteoporotic Fractures Research Group Lancet. 1999;354(9183):971-5.

3. Tsuda K, Nishio I, Masuyama Y. Bone mineral density in women with essentia hypertension. Am J Hypertens. 2001;14(7 Pt 1):704-7.

4. Rejnmark L, Vestergaard $P$, Mosekilde $L$. Reduced fracture risk in users of thiazide diuretics. Calcif Tissue Int. 2005;76(3):167-75.

5. Rejnmark L, Vestergaard P, Mosekilde L. Treatment with beta-blockers, ACE inhibitors, and calcium-channel blockers is associated with a reduced fracture risk: a nationwide case-control study. J Hypertens. 2006;24(3):581-9.

6. Rang HP, Dale MM, Ritter JM, Flower RJ. Rang \& Dale's Pharmacology. In: How drugs act; molecular aspects, $5^{\text {th }}$ ed UK: Churchill Livingstone, Edinburge, 2007;23-24.

7. Duncan RL, Akanbi KA, Farach-Carson MC. Calcium signals and calcium channels in osteoblastic cells. Semin Nephro. 1998;18(2):178-90.

8. Lieberherr $M$. Effects of vitamin $D_{3}$ metabolites on cytosolic free calcium in confluent mouse osteoblasts. J Biol Chem. 1987;262(27):13168-73.

9. Caffrey JM, Farach-Carson MC. Vitamin D3 metabolites modulate dihydropyridine -sensitive calcium currents in clonal rat osteosarcoma cells. J Biol Che. 1989;264(34):20265-74

10. Bidwell JP, Carter WB, Fryer MJ, Heath III H. Parathyroid hormone (PTH)induced intracellular $\mathrm{Ca}^{2+}$ signalling in naive and PTH desensitized osteoblastlike cells (ROS 17/2.8), pharmacological characterization and evidence for synchronous oscillation of intracellular $\mathrm{Ca}^{2+}$. Endocrinology. 1991;129(6):29933000 .

11. Moreau R. Hurst A, Lajeunesse D, Lapointe JY. Activation of maxi-K channels by parathyroid hormone and prostaglandin $E_{2}$ in human osteoblast bone cells. J Membr Bio. 1996;150(2):175-84.

12. Kurihara N, Ishizuka S, Kiyoki M, Haketa Y, Ikeda K, Kumegawa M. Effects of 1, 25-dihydroxyvitamin D3 on osteoblastic MC3T3-E1 cells. Endocrinology. 1986;118(3):940-7.

13. Nakatani $Y$, Fujita K, Hakeda $Y$, Kumegawa M, Kurihara N, Tsunoi M. (1986) Effects of parathyroid hormone on cAMP production and alkaline phosphatase activity in osteoblastic clone MC3T3-E1 cells. Biochem Biophys Res Commun. 1984;123(3):894-8

14. Kalu DN. The ovariectomized rat model of postmenopausal bone loss. Bone miner. 1991;15(3):175-91.

15. Barlet JP, Coxam V, Davicco MJ, Gaumet N. (1994). Animal models of postmenopausal osteoporosis. Reprod Nutr Dev. 1994;34(3):221-36.

16. Zahanich I, Boxberger S, Graf EM, Hempel U, Heubach JF, Ravens U. Molecular and functional expression of voltage-operated calcium channels during osteogenic differentiation of human mesenchymal stem cells. J Bone Miner Res. 2005;20(9):1637-46.

17. Anonymous. Guidance for Industry Estimating the Maximum Safe Starting
Dose in Initial Clinical Trials for Therapeutics in Adult Healthy Volunteers. U.S Department of Health and Human Services Food and Drug Administration Center for Drug Evaluation and Research (CDER) Pharmacol Toxicol. July 2005.

18. Cannon CZ, Kissling GE, Hoenerhoff MJ, King-Herbert AP, Blankenship-Paris T. Evaluation of dosages and routes of administration of tramadol analgesia in rats using hot-plate and tail-flick tests. Lab Anim (NY). 2010;39(11):342-51.

19. Lasota A. Danowska-Klonowska D. Experimental osteoporosis different methods of Ovariectomy in female white rats. Rocz Akad Med. Bialymst. 2004;49(Suppl 1):129-31.

20. SaadatParhizkar, Latiffah AL, Sabariah AR, Mohammad AD. HanachiParichehr Assessing estrogenic activity of Nigella sativa in ovariectomized rats using vaginal cornification assay. African J Pharm Pharmacol. 2011;5(2):137-42.

21. Miller GW, Burtis CA, Ash wood ER, Saunders WB Eds. Mineral and bone metabolism, In Tietz textbook of clinical chemistry, Philadelphia, 1994.

22. Reddy NP, Lakshmana M, Udupa UV. Antiosteoporotic activity of OST- 6 (Osteocare), a herbomineral preparation in calcium deficient ovariectomized rats. Phytother Res. 2004;18(1):25-9.

23. Shirwaikar A, Khan S, Malini S. Antiosteoporotic effect of ethanol extracts of Cissusquadrangularis Linn. On ovariectomized rat. J Ethnopharmacol. 2003;89(2-3):245-50.

24. Suzuki Y, Inoue T, Ra C. L-type $\mathrm{Ca}^{2+}$ channels, a new player in the regulation of $\mathrm{Ca}^{2+}$ signaling, cell actmrivation and cell survival in immune cells. Mollmmunol. 2010;47(4):640-8.

25. Tortora GJ, Derrickson HB. Principles of Anatomy and Physiology. United States of America. John Wiley and Sons Publishers. 2009;1715-7.

26. Pocotte SL, Ehrenstein G, Fitzpatrick LA. Role of calcium channels in parathyroid hormone secretion. Bone. 1995;16(4 Suppl):365S-72S

27. Preussner HT. Detecting celiac disease in your patients." American Family Physician. 1998;57(5):1023-34.

28. Iba K, Takada J, Yamashita T. The serum level of bone-specific alkaline phosphatase activity is associated with aortic calcification in osteoporosis patients. J Bone Miner Metab. 2004;22(6):594-6.

29. Zuccotti A, Clementi S, Reinbothe T, Torrente A, Vandael DH, Pirone A. Structural and functional differences between L-type calcium channels, crucial issues for future selective targeting. Trends Pharmacol Sci. 2011;32(6):366-75.

30. Katzung BG, Masters SB, Trevor AJ. Basic and Clinical pharmacology. In: Katzung BG editors. Vasodilators and the treatment of Angina Pectoris. $11^{\text {th }}$ ed New Delhi: Mcgraw Hill. 2009;191-208.

31. Guggino SE, Lajeunesse D, Wagner JA, Snyder SH. Bone remodeling signalled by a dihydropyridine- and phenylalkylamine-sensitive calcium channel. Proc Nat Acad Sci USA. 1989;86(8):2957-60.

32. Morain P, Peglion JL, Giesen-Crouse E. $\mathrm{Ca}^{2+}$ channel inhibition in a rat osteoblast-like cell line, UMR 106, by a new dihydropyridine derivative, S11568. Eur J Pharmacol. 1992;220(1):11-7.

33. Kruman I, Guo Q, Mattson MP. Calcium and reactive oxygen species mediate staurosporine-induced mitochondrial dysfunction and apoptosis in PC12 cells. J Neurosci Res. 1998;51(3):293-308. 